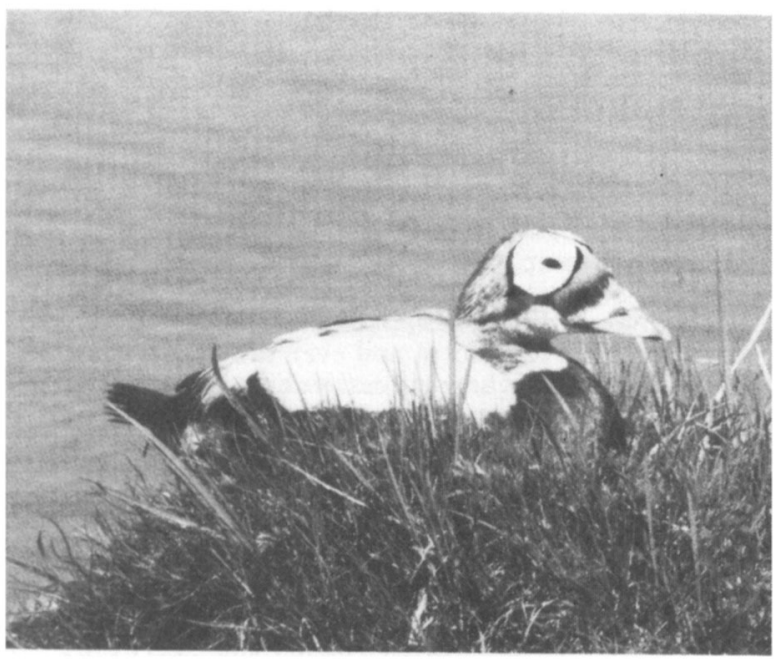

SPECTACLED EIDER Somateria

fischeri, the rarest of the eider ducks. These birds breed in Alaska and Siberia but their wintering grounds are unknown. This picture is reproduced from Waterfow 1 , a magnificent tome by Frank S. Todd (Harcourt, Brace, Jovanovich, £25) with photographs mostly in colour of the ducks, geese and waterfowl of the world. The wintering grounds are probably in the Bering Sea, but it is important to know where, for if, as seems likely, they collect in a comparatively small area, they could be very vulnerable.

\title{
The Hawaiian Goose, by Janet Kear and A.J. Berger. Poyser, £9.
}

In this scholarly book - dedicated to Sir Peter Scott, two of the enthusiasts responsible for the rescue of the species from extinction, and $\mathrm{Ah}$ Fat Lee, head of the propagating station at Pohakuloa - Dr Kear of the Wildfowl Trust and Professor Berger of the University of Hawaii give a detailed account of the habitat, behaviour, breeding and decline of the Hawaiian goose or nene (pronounced nay-nay), one of the endemic birds with which the archipelago was once so richly endowed. Later chapters discuss the problems of rearing the nene in captivity and of releasing captive-reared birds into their ancestral habitat. Finally a rigorous attempt is made to strike a balance of success and failure for the whole operation. The book is illustrated with 24 plates and 39 figures.

The once abundant nene population was reduced to perhaps 30 birds by modern guns, land development and introduced animals. The authorities were not, and still are not, particularly helpful, largely it would seem from ignorance, having proclaimed their intention to make Hawaii into 'one vast bird park'. As elsewhere, appreciation of wildlife has not been paralleled by appreciation of how much it costs not only in cash but also in restraining development. The species was saved by private initiative, particularly at Pohakuloa and Slimbridge. There are now about 2000 nene in the world and the danger of extinction seems remote. But there are many unanswered questions. What are the long-term effects of captivity on the genetic make-up and pathological condition of a restricted and inbred population? Numbers have been released on two islands, but can captive-bred birds and their descendants survive indefinitely in the wild? Might it not have been better to spend the money on eliminating predators in a desperate effort to protect the handful of wild survivors? Should the whole experiment have been carried out in large nene parks on Hawaii? On the positive side there is the great increase in knowledge of captive breeding and re-introduction and likewise a deeper appreciation of the full importance of field research both before and after release. This international project has encouraged other efforts at captive breeding and has aroused widespread interest in endangered species and methods of saving them. Whatever the final outcome there is much to be learnt from this experiment and, indeed, from this book. 